\author{
Research Article
}

Leopold Hrabovský* and David Dluhoš

\title{
Calibration of Transducers and of a Coil Compression Spring Constant on the Testing Equipment Simulating the Process of a Pallet Positioning in a Rack Cell
}

https://doi.org/10.1515/eng-2019-0072

Received Aug 27, 2019; accepted Sep 24, 2019

\begin{abstract}
In a parking house with KOMA TOWER computercontrolled automated parking system it happens that a control system is locked out of service after a pallet has failed to reach the required position during the shifting of pallets, loaded with cars, into rack cells.

In this paper is described testing equipment designed by the Institute of Transport, Faculty of Mechanical Engineering, VŠB Technical University of Ostrava for the purpose of simulating the process of pallets shifting into the rack cells in order that the frequency of error messages from the control system during the automated process of cars positioning in rack cells in the parking house may be limited.

The paper details two completed parts of the designed testing equipment which provide for the calibration of straingauge force transducers and for the detection of coil compressive spring compression in relation to acting pressure force.

The description of the third, principal design part will be provided in the next paper, together with the experimentally measured acting forces which generate, in both horizontal and vertical directions, as a pallet brake pulley rolls along a brake haunch length.
\end{abstract}

Keywords: testing equipment, calibration of transducers, spring compression, spring constant

\footnotetext{
*Corresponding Author: Leopold Hrabovský: VSB Technical University of Ostrava, Faculty of Mechanical Engineering, Institute of Transport, 17. listopadu 2172/15, 70800 Ostrava - Poruba, Czech Republic; Email: leopold.hrabovsky@vsb.cz

David Dluhoš: KOMA - Industry s.r.o., Ruská 514/41, 70602 Ostrava Vítkovice, Czech Republic; Email: david.dluhos@komaindustry.cz
}

\section{Introduction}

Oftentimes, urban areas become congested with an increasing number of office buildings, entertainment and sporting venues, restaurants, and residential living spaces, which ultimately limits the amount of parking for a growing population. As an alternative to traditional parking garages, which take up large amounts of space, garage parking systems provide urban parking solutions for any development.

The typical car park is full of wasteful space for one basic reason: people. The average car parking space is much larger than needed to park a car because of people. Extrawide parking spaces make parking easier and allow drivers and passengers to open car doors when parked. Similarly, the typical parking space is deeper and ceilings higher in order to accommodate drivers and pedestrians.

The largest wasted spaces in a car park are driving lanes and ramps. While these are necessary for people to drive to and from parking spaces, they contribute nothing to the space needed for parking cars. Other wasted space includes stairways, lifts/elevators, walkways and the added space for disabled parking - all to accommodate people. Automated Parking Systems (APS) eliminate the space typically wasted in car parks by removing drivers from the parking process.

APS provide a benefit that is a necessity for some mixed-use parking applications: inherently safe and secure parking. The unique design of an APS eliminates opportunities for crime and accidents that can occur in conventional car parks. Car theft and vandalism as well as personal crimes, such as robbery, assault and worse, are virtually impossible due to the driverless nature of parking in an APS.

APS eliminate much of the space wasted in traditional parking facilities by taking people out of the parking process and out of the parking area. An automatic mechanical system picks up cars and transports them to parking 
spaces. It reverses the process to return the cars to their drivers. This way APS utilize much smaller parking spaces and eliminate driving lanes, ramps, lifts, stairs, etc. The Automated Parking System also eliminates the need for people to be in the parking area. Drivers drop off and pick up cars in open and well-lighted entrances at ground level, eliminating the need to walk through often quite intimidating car parking areas.

APS can reduce $\mathrm{CO}_{2}$ emissions by $85 \%$ or more by eliminating the need for cars to drive and idle while searching for parking spaces. For parking garage development, APS typically require fewer building materials, a much smaller excavation volume, shorter construction time and reduced construction disruption. For the ultimate in sustainability, Automated Parking Systems are most often the least expensive option for underground parking garages.

Several organizations in the world manage the planning and implementation of fully automated car parking systems globally, offering innovative car parking solutions for everyone. The nature of automated parking technology combines maximum storage capacity and optimum user comfort, with zero sacrifice for vehicle or customer safety.

WESTFALIA [1] offers both pallet and non-pallet parking systems. There are pros and cons with each approach, although it is safe to say that non-pallet solutions appear to be gaining popularity. This is because empty pallet handling is eliminated and the technology itself has become more reliable as it has matured.

The palletless APS uses Westfalia's Satellite Technology that can adjust to the length of the car's wheelbase, allowing the system to handle multiple car sizes.

Once the vehicle is positioned in the transfer cabin and the driver and passengers have cleared it, the Satellite drives under the car where the wheels are clamped, transporting the car onto the shuttle. Unlike pallet-supported systems, the vehicle is transported into the parking garage and positioned on a concrete deck. Building construction can be based on concrete or steel, depending on location and construction costs.

The elevator / shuttle system MasterVario LS [2] provides similarly flexible features as the shelf system, but they have the advantage that they can be used for a larger number of parking spaces. The flexible arrangement of one or multiple elevators for vertical transport and the use of independent shuttles taking over the horizontal distribution of the cars in the storage area allow a larger number of parking spaces, for which normally multiple system would be necessary. The arrangement in the levels can be as onerow or two-row-system parallel to the shuttles.

In the above-ground parking house with KOMA TOWER computer-controlled automated parking system, placed on pallets, cars are stored in rack cells both side by side and one above the other [3, 4].

When the pallets are shifted from a lifting device platform to rack cells on either side of the lifting device by means of a chain conveyer in short time intervals, it happens that some pallet fails to reach the required position and, as a result, an error message is displayed and the control system of the KOMA TOWER computer controlled automated parking system is locked out of service.

The cause for an error message in many cases is that a cut-out of circular segment shape in a so called brake haunch [4], which is screwed on the bottom side of the pallet being stacked, after a pallet has been shifted to the particular floor by the lifting device, fails to fit into a pallet brake pulley screwed on the parking house storage rack steel girders.

Two design versions of the pallet brake are available (see Figure 1), both versions consisting of three basic parts (see Figure 2) a brake body $\underline{1}$, brake support 2 and coil compressive spring 3 .

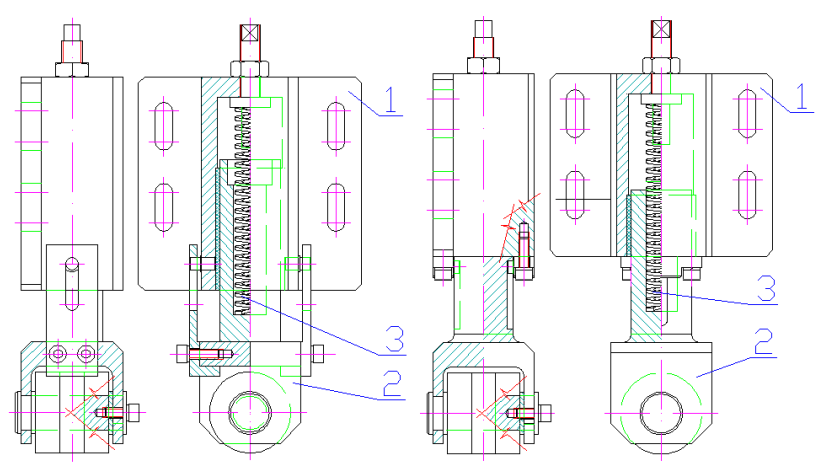

Figure 1: Pallet brake
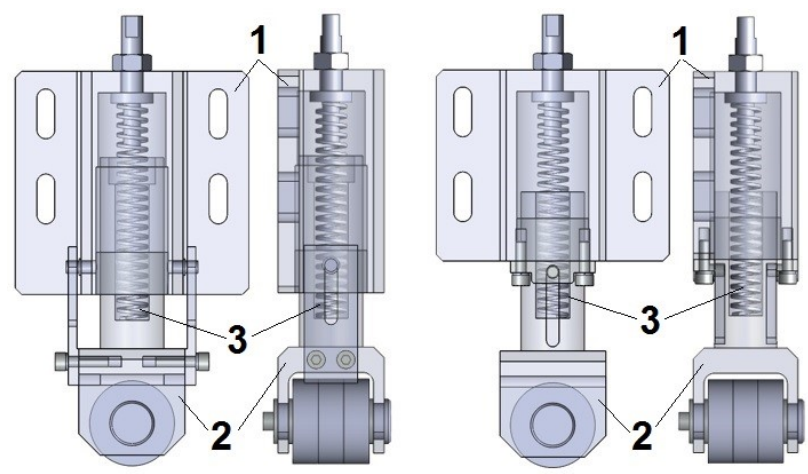

Figure 2: Pallet brake design versions 


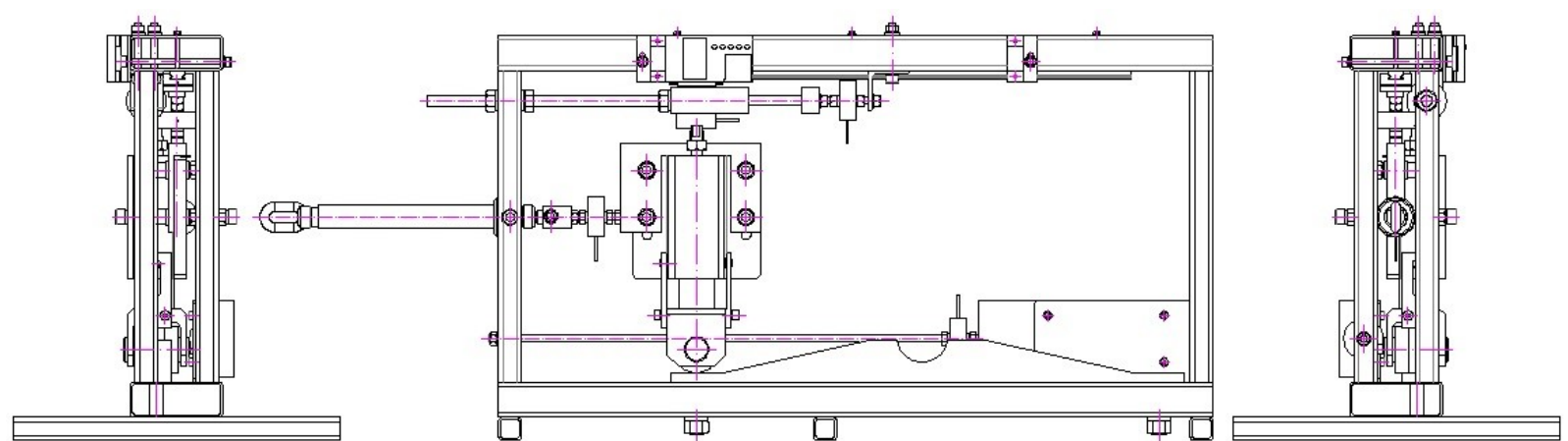

Figure 3: Testing equipment for the pallet arresting system

\section{Testing Equipment for a Pallet Arresting System}

To verify the functionality of the pallet arresting system applied in the parking house with KOMA TOWER computercontrolled automated parking system, and to obtain actual information on the magnitudes of acting pressure forces which generate in the pallet arresting system when the pallet is being shifted to or out of its parking position, drawings of the assembly of the pallet arresting system testing equipment have been prepared and the testing equipment designed, see Figure 3.

The testing equipment for the pallet arresting system (see Figure 9 [4] and Figure 10 for a 3D model created in SolidWorks Premium 2012 SP 5.0 environment), was so designed to enable the following four primary functions:

- the calibration of strain-gauge force transducers,

- the detection of the coil compressive spring distortion value in relation to the compressive force acting in the spring,

- the detection of the values of acting forces which generate in the horizontal and vertical directions when a pallet brake pulley rolls along a brake haunch, and

- the detection of the values of actually acting forces as these develop in both horizontal and vertical directions when a pallet bracket pulley is shifted out of the cut-out of a circular segment shape in a bracket haunch, and their comparison with the forces determined theoretically [4].

\section{Calibration of Strain-Gauge Based Force Transducers}

The testing equipment for the pallet arresting system allows for the calibration of force transducers MCF30 [5]. The equipment consists of a frame structure welded of thinwalled hollow steel sections, see Figure 4, of which the upper 1.1 and lower 1.2 horizontal thin-walled hollow sections are of rectangular cross sections sized $80 \mathrm{~mm} \times 30$ $\mathrm{mm}$, wall thickness $3 \mathrm{~mm}$ and total length $613.6 \mathrm{~mm}$ each.
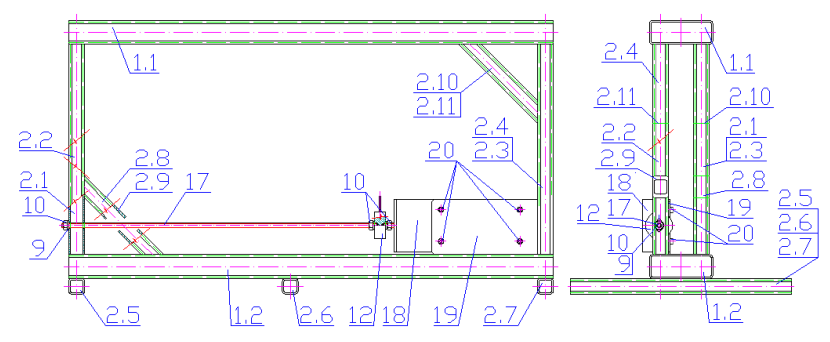

Figure 4: Testing equipment for the calibration of force transducers, 2D design

Vertical thin-walled hollow steel sections $\underline{2.1}$ through to 2.4 of the frame structure are of square sections $20 \mathrm{~mm}$ $\times 20 \mathrm{~mm}$, wall thickness $2 \mathrm{~mm}$ and length $266.5 \mathrm{~mm}$.

Stiffeners $\underline{2.8}$ and $\underline{2.9}$, and $\underline{2.10}$ and 2.11 are used in the left-hand lower and right-hand upper corners of the calibration equipment respectively, made of thin-walled hollow square sections $20 \mathrm{~mm} \times 20 \mathrm{~mm}$, wall thickness $2 \mathrm{~mm}$ and length $141.4 \mathrm{~mm} / 101.4 \mathrm{~mm}$.

Welded on the bottom of section 1.2, three thin-walled hollow steel sections 2.5 through to 2.7 , sized $20 \mathrm{~mm} \times 20$ $\mathrm{mm}$, wall thickness $2 \mathrm{~mm}$ and total length $280 \mathrm{~mm}$, prevent the testing equipment steel structure from the loss of stability (a tilting prevention). The distance between the left-hand vertical surface of section 2.6 and the left-hand 
vertical edge of section $\underline{1.2}$ is $270.6 \mathrm{~mm}$ (see the left-hand view in Figure 4).

A dynamometer holder 19 is welded to the right-hand vertical surface of vertical section 2.4 and to upper surface of section 1.2 (see the right-hand view in Figure 4), having its right-hand vertical edge situated $4 \mathrm{~mm}$ from the section 2.3 right-hand vertical edge (see the left-hand view in Figure 4). Through four holes ( $4 \mathrm{~mm}$ in diameter), which are drilled in the dynamometer holder 19 , pass bolts 20 , having their threaded portions screwed into tapped holes M4 on the rear surface of dynamometer $\underline{18}$ [6].

From the face of dynamometer 18 protrudes a stem of threaded bolt M6 fitted with a nut M6. The end, threaded portion of the dynamometer $\underline{18}$ bolt is screwed into the tapped M6 hole ( $5 \mathrm{~mm}$ in depth) in one of the force transducer $\underline{12}$ faces. Another tapped hole (5 $\mathrm{mm}$ in depth) is present in the opposite face of force transducer 12 . Into this hole is screwed one end of a threaded rod M6, 17 (total length $400 \mathrm{~mm}$ ). A hexagon nut M6, 10 prevents the force transducer 12 from angular displacement towards the threaded rod. The threaded rod 17 passes through a hole $(7$ $\mathrm{mm}$ in dia.) drilled in vertical section 2.2 (distance of the hole axis from the section 2.2 lower edge is $37 \mathrm{~mm}$ ).

The end portion of threaded rod 17, protruding from the hole in section 2.2, is provided with a washing 9 and nut M6 10.

The equipment designed for the calibration of force transducers MCF30 - $500 \mathrm{~N}$ is shown in Figure 5.

Two force transducers MCF30 - $500 \mathrm{~N}, \underline{12}$ are provided with cables LifYDY $4 \times 0.05 \mathrm{~mm}, 2 \mathrm{~m}$ in length fitted with D-Sub 9-Pin computer pin plugs. Soldered to the cable end portions, the pin plugs are connected to a measuring device DEWESoft DS-NET. Transducers $\underline{12}$ have been calibrated one after another in the environment of DEWESoft X2 SP5 software installed in a PC. The pushing / pulling force acting on transducers $\underline{12}$ being calibrated was pro-

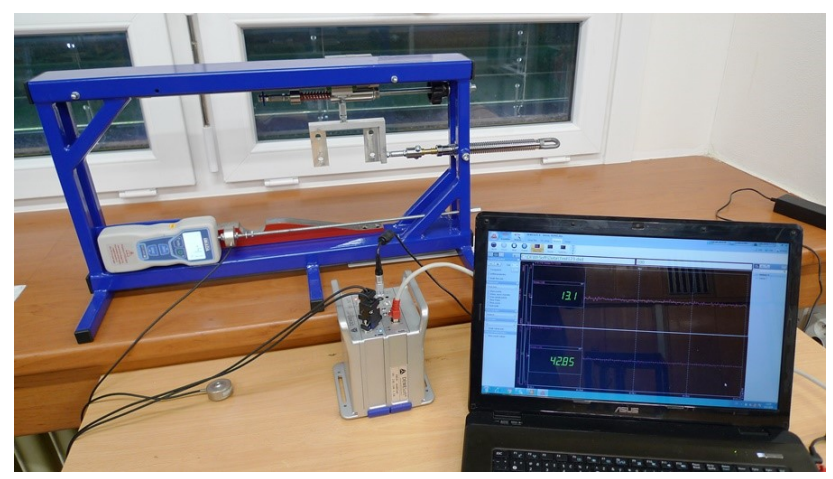

Figure 5: Testing equipment for the calibration of force transducers MCF30 - $500 \mathrm{~N}$ duced by tightening the nut M6, 10 on the threaded rod $\underline{17}$ towards the vertical section 2.2 of the steel frame structure and read on a digital dynamometer $\underline{18}$. The transducer $\underline{12}$ being calibrated was screwed on the threaded part M6 of the digital dynamometer 18 and the end part of threaded $\operatorname{rod} 17$.

\section{Detection of the cylindrical coil compressive spring compression in relation to the amount of pushing force applied}

The frame structure of testing equipment has an L-rod 16 welded to the bottom of upper section 1.1 (the distance of the L-rod 16 face from the left-hand edge of section 1.1 is $317.8 \mathrm{~mm}$ ). In the L-rod 16 face is drilled a hole $6 \mathrm{~mm}$ in diameter, having its horizontal axis located $26 \mathrm{~mm}$ from the section 1.1 bottom and vertical axis $14 \mathrm{~mm}$ from the section 1.1 surface.

Through the hole of $6 \mathrm{~mm}$ in L-rod $\underline{16}$ passes a threaded $\operatorname{rod} \underline{11}$, having its end section provided with a washer $\underline{9}$ and nut 10 from the right-hand side of the L-rod 16 vertical arm (see the left-hand view in Figure 6). From the left-hand side of the L-rod $\underline{16}$ vertical arm, the threaded rod 11 protruding from the hole of $6 \mathrm{~mm}$ is provided with another nut $\underline{10}$ (the right-hand end portion of threaded rod $\underline{11}$ is firmly attached to the L-rod 16 by means of the two nuts $\underline{10}$ ).

The left-hand end section of threaded rod 11 (total 25 $\mathrm{mm}$ in length) is screwed into the tapped hole M6 (5 $\mathrm{mm}$ in depth) in one of the force transducer 12 faces.

The opposite face of force transducer $\underline{12}$ has another tapped hole M6 ( $5 \mathrm{~mm}$ in depth) performed for one end of the threaded rod M6, $\underline{11}$ (total $25 \mathrm{~mm}$ in length) to be screwed in. A hexagon nut M6, 10 prevents the force transducer $\underline{12}$ from angular displacement in relation to
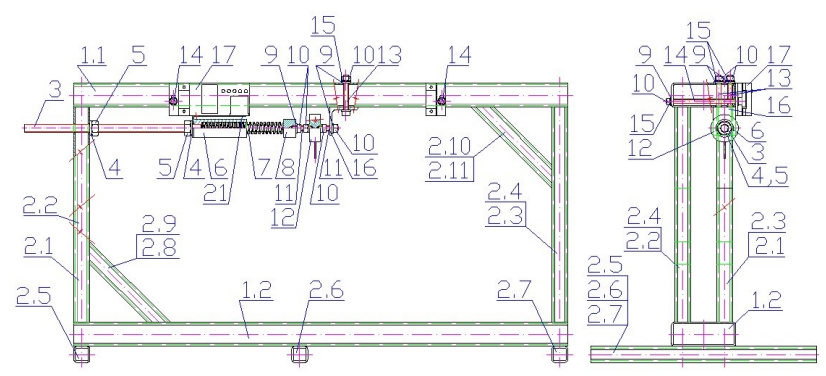

Figure 6: Equipment for the determination of a compression spring constant, 2D design 

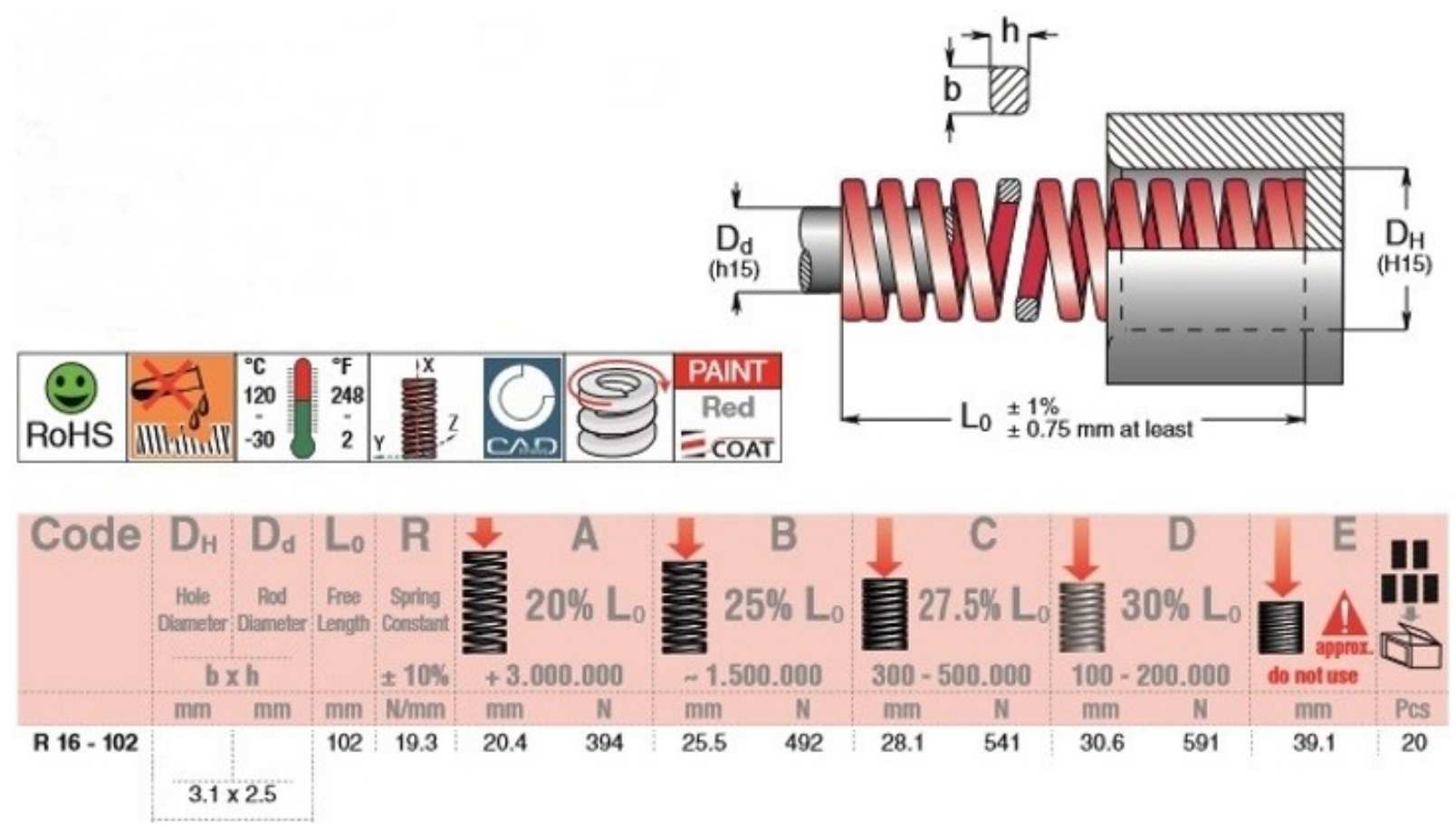

Figure 7: Basic parameters of coil compressive spring R16-102 [7]

both threaded rods 11 . The other, left-hand end portion of threaded rod 11 is screwed into the M6 tapped hole $(5 \mathrm{~mm}$ in depth) in the pin face of spring $\underline{8}$. A washer 9 and nut $\underline{10}$ prevent the left-hand end of threaded rod 11 from screwing off from the tapped hole in spring $\underline{8}$ pin.

Spring $\underline{7}$ has one side slid on the end portion of the spring 8 pin (8 $\mathrm{mm}$ in diameter and $46 \mathrm{~mm}$ in length) [8] while the other is inserted into a hole $(16 \mathrm{~mm}$ in diameter and $56 \mathrm{~mm}$ in length) in a spring $\underline{6}$ hub. The spring $\underline{6}$ hub has a tapped hole M10, $10 \mathrm{~mm}$ in depth, performed in its face, into which is screwed one end (the right-hand one, see the left-hand view in Figure 6) of threaded rod $\underline{3}$ (of total length $220 \mathrm{~mm}$ ). A washer $\underline{4}$ and nut $\underline{5}$ prevent the righthand end of the threaded rod 3 from screwing out of the spring 6 hub tapped hole.

The left-hand end portion of the threaded rod 3 passes through a hole $10 \mathrm{~mm}$ (having its horizontal axis situated $26 \mathrm{~mm}$ from the upper end edge of section 2.1 and vertical axis $14 \mathrm{~mm}$ from both the left- and right-hand edges of section 2.1 vertical surface, see the right-hand view in Figure 6) in the frame structure section 2.1. The washer $\underline{4}$ and nut $\underline{5}$ mounted on the threaded rod 3 from the inner side of section 2.1 (see left-hand view in Figure 6) serve for securing the spring $\underline{7}$ (of total length $102 \mathrm{~mm}$ ) distortion.

There are six tapped holes M3 in the rear surface of position sensor 17 [7] rider. To these holes, using screws M3 $\times 5 \mathrm{~mm}$, the face of linking part $\underline{21}$ is attached; the linking part is made of sheet metal $1 \mathrm{~mm}$ thick by bending.
The linking part 21, through its hole of $10 \mathrm{~mm}$, is slid on a threaded rod 3 and attached in between the hub face of spring $\underline{6}$ and washer 5 .

When turning the nut $\underline{5}$ on the threaded rod $\underline{3}$ in relevant direction, the spring $\underline{7}$ becomes distorted (compressed). Thanks to the mechanical connection of the spring 6 hub with the position sensor 17 rider by means of the linking part 21, the instantaneous magnitude of the spring 7 compression is read on the display of the digital position sensor $\underline{17}$.

In Figure 7 are shown basic dimensional parameters of spring $\underline{7}[7]$ and data about pushing forces, $\mathrm{F}_{i}[\mathrm{~N}]$ acting during the spring $\underline{7}$ compression, $\mathrm{s}_{i}[\mathrm{~mm}]$ by $20 \%\left(\mathrm{~s}_{20}=\right.$ $(102 / 100) .20=1.02 .20=20.4 \mathrm{~mm})$; by $25 \%\left(\mathrm{~s}_{25}=1.02 .25\right.$ $=25.5 \mathrm{~mm})$; by $27.5 \%\left(\mathrm{~s}_{27.5}=1.02 .27 .5=28.1 \mathrm{~mm}\right)$, and by $30 \%\left(\mathrm{~s}_{30}=1.02 .30=30.6 \mathrm{~mm}\right)$; the spring free length $\mathrm{L}_{0}$ $=102 \mathrm{~mm}$. From this data can be determined a spring R16102 constant, $\mathrm{k}_{p}[\mathrm{~N} / \mathrm{mm}]$ declared by the manufacturer: $\mathrm{k}_{p}$ $=\mathrm{F}_{i} / \mathrm{s}_{i} \Rightarrow \mathrm{k}_{p}=\mathrm{F}_{20} / \mathrm{s}_{20}=394 / 20.4=19.3 \mathrm{~N} / \mathrm{mm}$ to $\mathrm{k}_{p}=$ $\mathrm{F}_{30} / \mathrm{s}_{30}=591 / 30.6=19.3 \mathrm{~N} / \mathrm{mm}$, which is stated in a coil compressive springs catalogue [7].

In the KOMA TOWER parking house are used red coil compressive springs $\underline{7}$ manufactured by Eichler Company a. s., see reference marking 3 in Figure 2. Identified as R16102 , these springs have a spring constant $19.3 \mathrm{~N} / \mathrm{mm}$ specified in the catalogue [7]. In paper [4] are quantified the acting forces values corresponding to green coil compressive 


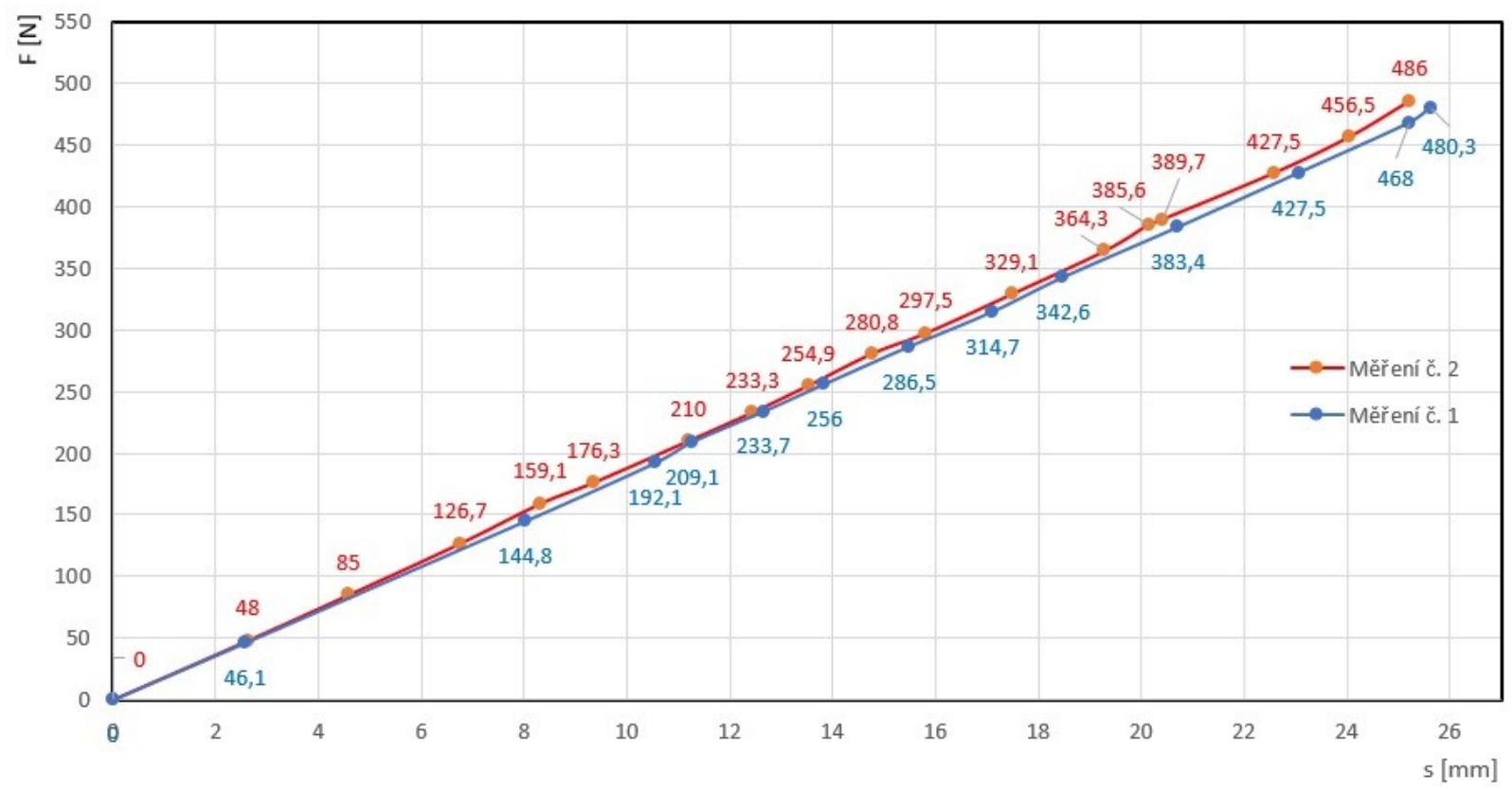

Figure 8: Spring compression vs. compressive force

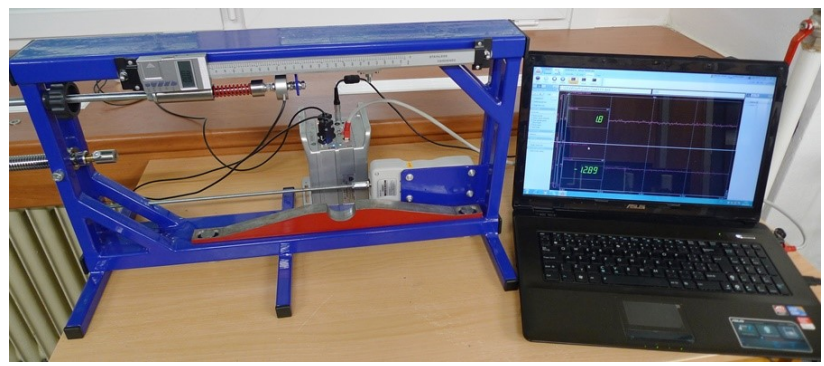

Figure 9: Testing equipment for the calibration of force transducers

springs of spring constant $7.4 \mathrm{~N} / \mathrm{mm}$, identified as V16-102 in the catalogue [7].

To verify the calculated [4] theoretical values of the vertical and horizontal forces needed for the pallet brake pulley to disengage from the cut-out of a circular segment shape in the brake haunch, and to compare them with the values found experimentally by measuring on the testing equipment (see Figure 3 and Figure 10), the magnitudes of acting forces given in paper [4] need to be re-calculated to be consistent with the spring constant $19.3 \mathrm{~N} / \mathrm{mm}$.

During experimental measuring on the testing equipment, compressive force, $\mathrm{F}[\mathrm{N}]$ developed by the spring 7 compression is picked up by a force transducer MCF30 $500 \mathrm{~N} \underline{12}$, fitted with a cable LifYDY $4 \times 0.05 \mathrm{~mm}$ (of total length $2 \mathrm{~m}$ ) having a D-Sub 9-Pin computer pin plug soldered on its end section. The pin plug is connected to a measuring device DEWESoft DS-NET. From the data obtained experimentally, i.e. by measurements made on the testing equipment, see Table 1 , the constant, $\mathrm{k}_{m p}$ [N/mm] of the examined spring $\underline{7}$ could have been determined $\left(\mathrm{k}_{m p}\right.$ $=\mathrm{F} / \mathrm{s}=477.1 / 25.25=18.9 \mathrm{~N} / \mathrm{mm}$ ), see Figure 8. The spring $\underline{7}$ values of $\mathrm{k}_{m p}[\mathrm{~N} / \mathrm{mm}]$ determined by calculations from the measured values (spring compression, $\mathrm{s}[\mathrm{mm}]$ and compressive forces, $\mathrm{F}[\mathrm{N}]$ ) can be verified with the spring constant, $\mathrm{k}_{p}[\mathrm{~N} / \mathrm{mm}]$ given in the spring $\underline{7}$ manufacturer's catalogue (see Figure 7) [7].

The part of the testing equipment designed for the determination of spring R16-102 constant is shown in Figure 9.

In Table 1 and Table 2 are given the measured values of the forces acting during the spring 7 compression (maximum and minimum values obtained from all measurements performed) for only two selected measurements from the entire range of measurements being carried out.

In Table 1 are partial constants, $\mathrm{k}_{p i}[\mathrm{~N} / \mathrm{mm}]$ of spring R16-102 calculated for the spring particular compressions $\mathrm{s}_{i}[\mathrm{~mm}]$ at known compressive force $\mathrm{F}_{i}[\mathrm{~N}]$ acting on the spring.

From the given values of spring $\underline{7}$ constants, $\mathrm{k}_{p i}$ $[\mathrm{N} / \mathrm{mm}]$ as calculated for partial compressions was determined a mean of spring R16-102 constant, $\mathrm{k}_{p}=18.42 \mathrm{~N} / \mathrm{mm}$ for the minimum values achieved in all taken measurements, together with the calculation of an arithmetic mean standard deviation, $\mathrm{s}_{\text {on }}[\mathrm{N} / \mathrm{mm}]$, see relation (1), and limit error, $\chi_{\alpha, n}[\mathrm{~N} / \mathrm{mm}]$, see relation (2).

An arithmetic mean standard deviation, $\mathrm{s}_{\text {on }}[\mathrm{N} / \mathrm{mm}]$ for " $n$ " number of measurements has been calculated ac- 
Table 1: Experimental measurement No. 1

\begin{tabular}{|c|c|c|c|c|c|c|c|c|c|}
\hline Spring pushing & $s[\mathrm{~mm}]$ & 2,57 & 8,02 & 10,55 & 11,27 & 12,65 & 13,84 & 15,49 & 17,11 \\
\hline $\begin{array}{l}\text { Compressive } \\
\text { force }\end{array}$ & $\mathrm{F}[\mathrm{N}]$ & 46,1 & 144,8 & 192,1 & 209,1 & 233,7 & 256,0 & 286,5 & 314,7 \\
\hline Spring constant & $\mathrm{k}_{p i}[\mathrm{~N} / \mathrm{mm}]$ & 17,94 & 18,05 & 18,21 & 18,55 & 18,47 & 18,50 & 18,50 & 18,39 \\
\hline \multicolumn{2}{|c|}{$\Delta_{\mathbf{i}}=\mathbf{k}_{\mathbf{p i}}-\mathbf{k}_{\mathbf{p}}[\mathbf{N} / \mathbf{m m}]$} & $-0,49$ & $-0,37$ & $-0,21$ & 0,13 & 0,05 & 0,07 & 0,07 & $-0,03$ \\
\hline \multicolumn{2}{|c|}{$\Delta_{\mathbf{i}}^{2}\left[\mathbf{N}^{2} \mathbf{b f} / \mathbf{m m}^{2}\right]$} & 0,24 & 0,14 & 0,05 & 0,02 & 0,00 & 0,01 & 0,01 & 0,00 \\
\hline \multicolumn{2}{|c|}{$\left|\Delta_{\mathbf{i}}\right|=\mathbf{k}_{\mathbf{p i}}-\mathbf{k}_{\mathbf{p}}[\mathbf{N} / \mathbf{m m}]$} & 0,49 & 0,37 & 0,21 & 0,13 & 0,05 & 0,07 & 0,07 & 0,03 \\
\hline Spring pushing & $\mathrm{s}[\mathrm{mm}]$ & 18,48 & 20,72 & 23,07 & 25,21 & 25,62 & & & \\
\hline \multicolumn{10}{|l|}{ force } \\
\hline Spring constant & $\mathrm{k}_{p i}[\mathrm{~N} / \mathrm{mm}]$ & 18,54 & 18,50 & 18,53 & 18,56 & 18,75 & $\Sigma \mathrm{k}_{p i}=239,50$ & $\mathrm{k}_{p}=\Sigma \mathrm{k}_{p}$ & $=18,42$ \\
\hline \multirow{2}{*}{\multicolumn{2}{|c|}{$\begin{array}{l}\Delta_{\mathbf{i}}=\mathbf{k}_{\mathbf{p i}}-\mathbf{k}_{\mathbf{p}}[\mathbf{N} / \mathbf{m m}] \\
\Delta_{\mathbf{i}}^{2}\left[\mathbf{N}^{2} / \mathbf{m m}^{2}\right]\end{array}$}} & 0,12 & 0,08 & 0,11 & 0,14 & 0,32 & $\Sigma \Delta_{i}=0$ & & \\
\hline & & 0,01 & 0,01 & 0,01 & 0,02 & 0,11 & $\Sigma \Delta_{i}^{2}=0,06$ & & \\
\hline \multicolumn{2}{|c|}{$\left|\Delta_{\mathbf{i}}\right|=\mathbf{k}_{\mathbf{p i}}-\mathbf{k}_{\mathbf{p}}[\mathbf{N} / \mathbf{m m}]$} & 0,12 & 0,08 & 0,11 & 0,14 & 0,32 & $\Sigma\left|\Delta_{i}\right|=2,20$ & & \\
\hline
\end{tabular}

Table 2: Experimental measurement No. 2

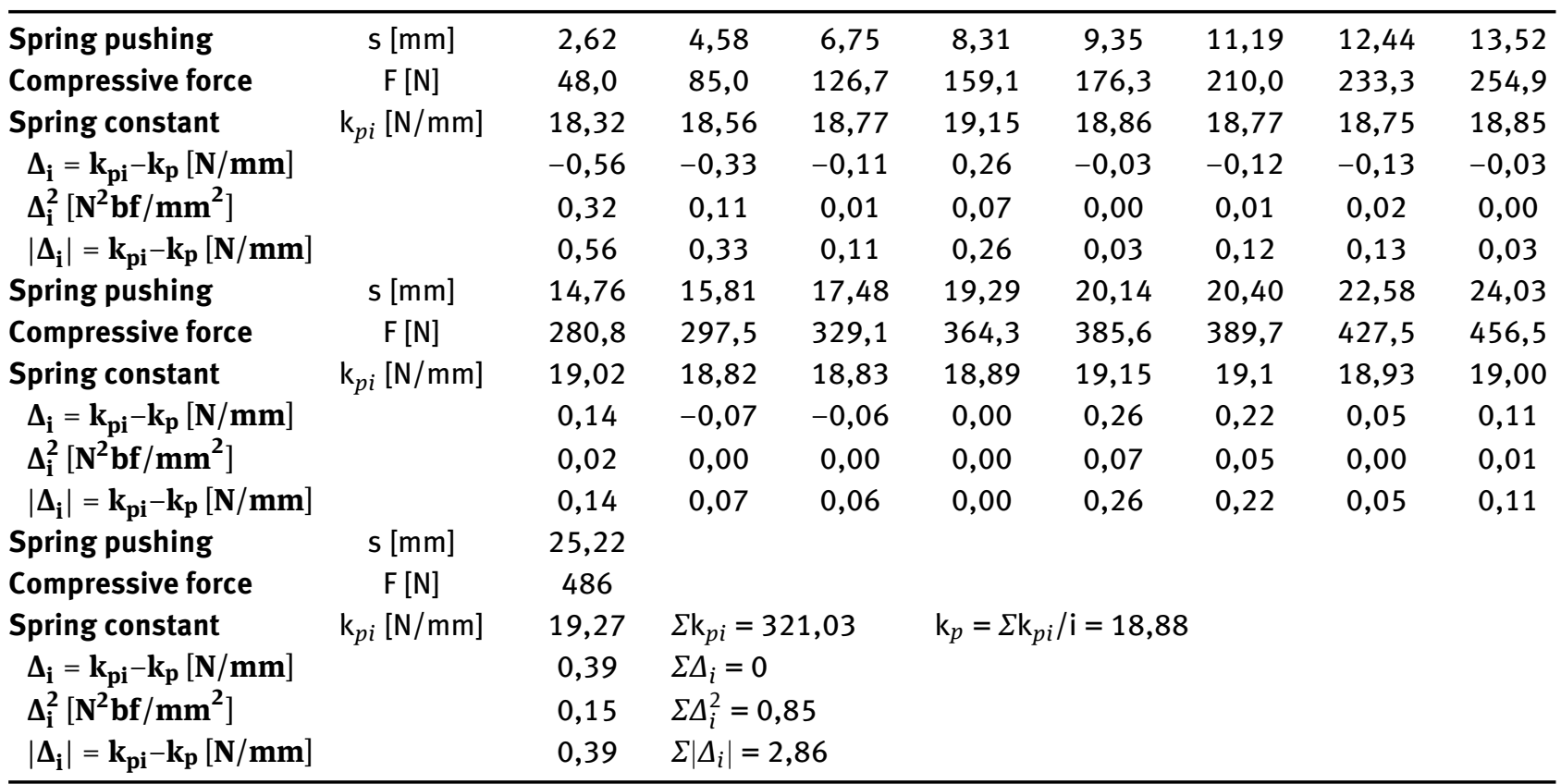

cording to $[7,(38)]$ in relation (1).

$$
\begin{aligned}
\mathrm{S}_{013} & =\frac{5}{4} \frac{\sum_{\mathrm{i}=1}^{\mathrm{n}}\left|\Delta_{\mathrm{i}}\right|}{\mathrm{n} \cdot \sqrt{\mathrm{n}-1}}=\frac{5}{4} \frac{\sum_{\mathrm{i}=1}^{13}\left|\Delta_{\mathrm{i}}\right|}{13 \sqrt{13-1}} \\
& =\frac{5}{4} \frac{2,20}{13.3,46}=0,06 \mathrm{~N} / \mathrm{mm}
\end{aligned}
$$

The table of Student's t-distribution critical values $[10$, page 35] assigns Student's coefficient, $\mathrm{t}_{\alpha, n}=3.06$ to risk, $\alpha$ $=1 \%$ and number of measurements, $\mathrm{n}=1$. Limit error, $\chi_{\alpha, n}$ $[\mathrm{N} / \mathrm{mm}]$ is calculated in relation (2) [11].

$$
\chi_{1 \%, 13}=t_{1 \%, 13} \cdot s_{013}=3,06 \cdot 0,06=0,19 \mathrm{~N} / \mathrm{mm}
$$

From measurement \#1 of the spring $\underline{7}$ constant, see Table 1 , was determined spring constant, $\mathrm{k}_{p}=18.42 \pm 0.18$ $\mathrm{N} / \mathrm{mm}$ (interval $18.24 \mathrm{~N} / \mathrm{mm} ; 18.60 \mathrm{~N} / \mathrm{mm}$ ).

Standard deviation of arithmetic mean, $\mathrm{s}_{o n}[\mathrm{~N} / \mathrm{mm}]$ (per [10, (30)]) follows from relation (3).

$$
\mathrm{s}_{013}=\sqrt{\frac{\sum_{\mathrm{i}=1}^{\mathrm{n}} \Delta_{\mathrm{i}}^{2}}{\mathrm{n}(\mathrm{n}-1)}}=\sqrt{\frac{0,06}{13(13-1)}}=0,02 \mathrm{~N} / \mathrm{mm}
$$

In relation (5) is calculated the arithmetic mean standard deviation, $\mathrm{s}_{o n}[\mathrm{~N} / \mathrm{mm}]$ from a sample standard devia- 


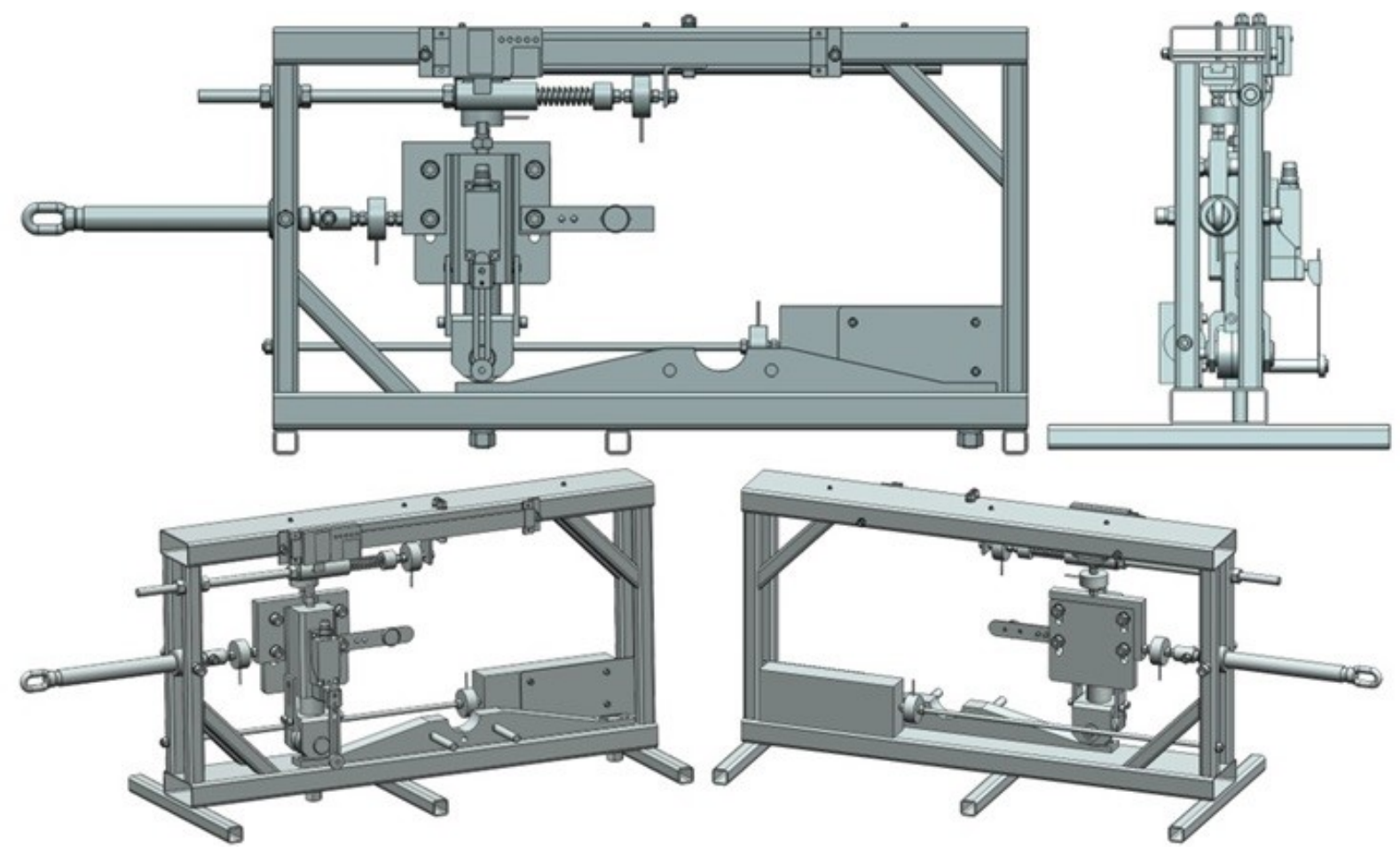

Figure 10: Equipment for the testing of pallets arresting system

tion, $\mathrm{s}_{\text {von }}[\mathrm{N} / \mathrm{mm}](4)$.

$$
\begin{gathered}
\mathrm{s}_{\mathrm{v} 013}=\sqrt{\frac{\sum_{\mathrm{i}=1}^{\mathrm{n}} \Delta_{\mathrm{i}}^{2}}{\mathrm{n}-1}}=\sqrt{\frac{0,06}{13-1}}=0,07 \mathrm{~N} / \mathrm{mm} \\
\mathrm{s}_{013}=\frac{\mathrm{S}_{\mathrm{vo} 13}}{\sqrt{13}}=\frac{0,07}{3,61}=0,02 \mathrm{~N} / \mathrm{mm}
\end{gathered}
$$

From the spring 7 constant values, $\mathrm{k}_{p i}[\mathrm{~N} / \mathrm{mm}]$, see Table 2, calculated for " $n$ " partial spring compressions was determined the mean of spring R16-102, $\underline{7}$ constant, $\mathrm{k}_{p}=$ $18.88 \mathrm{~N} / \mathrm{mm}$ for the maximum values achieved in all performed measurements, arithmetic mean standard deviation, $s_{o n}[\mathrm{~N} / \mathrm{mm}]$, see relation (6), and limit error, $\chi_{\alpha, n}$ $[\mathrm{N} / \mathrm{mm}]$, see relation $(7)$.

$$
\begin{aligned}
\mathrm{S}_{017} & =\frac{5}{4} \frac{\sum_{\mathrm{i}=1}^{\mathrm{n}}\left|\Delta_{\mathrm{i}}\right|}{\mathrm{n} \sqrt{\mathrm{n}-1}}=\frac{5}{4} \frac{\sum_{\mathrm{i}=1}^{17}\left|\Delta_{\mathrm{i}}\right|}{17 \sqrt{17-1}} \\
& =\frac{5}{4} \frac{2,86}{17 \cdot 4}=0,05 \mathrm{~N} / \mathrm{mm}
\end{aligned}
$$

The table of Student's t-distribution critical values [10, page 35] assigns a Student's coefficient, $\mathrm{t}_{\alpha, n}=2.12$ to a risk, $\alpha=5 \%$ and number of measurements $\mathrm{n}=17$. Limit error, $\chi_{\alpha, n}[\mathrm{~N} / \mathrm{mm}]$ is calculated from relation $(7)$.

$$
u p \chi_{5 \%, 17}=\mathrm{t}_{5 \%, 17} \cdot \mathrm{s}_{017}=2,12 \cdot 0,05=0,11 \mathrm{~N} / \mathrm{mm}
$$

From the measurement of spring $\underline{7}$ constant, see Table 2 , the spring constant, $\mathrm{k}_{p}=18.88 \pm 0.11 \mathrm{~N} / \mathrm{mm}$ was established (interval $18.76 \mathrm{~N} / \mathrm{mm} ; 18.99 \mathrm{~N} / \mathrm{mm}$ ).

Arithmetic mean standard deviation, $\mathrm{s}_{\text {on }}[\mathrm{N} / \mathrm{mm}]$ (per $[10,(30)])$.

$$
\mathrm{S}_{017}=\sqrt{\frac{\sum_{\mathrm{i}=1}^{\mathrm{n}} \Delta_{\mathrm{i}}^{2}}{\mathrm{n} \cdot(\mathrm{n}-1)}}=\sqrt{\frac{0,85}{17(17-1)}}=0,06 \mathrm{~N} / \mathrm{mm}
$$

The calculation of arithmetic mean standard deviation, $s_{o n}[\mathrm{~N} / \mathrm{mm}]$, see relation (9), from a sample standard deviation, $\mathrm{s}_{v o n}[\mathrm{~N} / \mathrm{mm}](10)$.

$$
\begin{gathered}
\mathrm{s}_{\mathrm{vo17}}=\sqrt{\frac{\sum_{\mathrm{i}=1}^{\mathrm{n}} \Delta_{\mathrm{i}}^{2}}{\mathrm{n}-1}}=\sqrt{\frac{0,85}{17-1}}=0,23 \mathrm{~N} / \mathrm{mm} \\
\mathrm{s}_{017}=\frac{\mathrm{s}_{\mathrm{vo} 17}}{\sqrt{17}}=\frac{0,23}{3,61}=0,06 \mathrm{~N} / \mathrm{mm}
\end{gathered}
$$

A 3D model of equipment for the testing of pallet arresting system as created in SolidWorks Premium 2012 SP 5.0 environment is shown in Figure 10. When implemented, two strain-gauge based transducers attached to the test equipment will detect instantaneous values of horizontal and vertical forces acting on the pallet brake during the brake pulley rolling along the top surface of bracket haunch. 
The implemented testing equipment will also provide for experimental finding of values of the forces acting both horizontally and vertically on the pallet brake when the pallet brake pulley is pushed out of the cut-out of circular shape in the brake haunch. The values found by measuring will be verified against those determined theoretically in paper [4].

It is our effort to limit the above described negative behaviour of pallet arresting system as much as possible since the lock-out of arresting system affects adversely the automated process of parking and retrieval of cars in the KOMA TOWER parking house. Currently, a sensor ME 8108 (or ME - 81 12) [12] manufactured by MOUJEN is installed on a brake body.

At a time when the brake pulley is in the cut-out of circular segment shape in the brake haunch, the sensor forwards information to control system which immediately decelerates motor speed thus preventing the pallet brake pulley from going out of the brake haunch cut-out.

The description of equipment for the testing of pallet arresting system, specification of transducers applied and recording of acting forces in DEWESoft environment of DEWESoft DS-NET measuring device will be provided in the paper named "Equipment for the testing of pallet arresting system" after its completion.

\section{Conclusion}

Parking houses with controlled processes of car parking and retrieval and sophisticated technologies may help to alleviate today's lack of standard parking spaces.

In the KOMA TOWER parking house, for a driver, the process of automated parking consists just in driving the car on a transport pallet inside an entrance space. The pallet loaded with car is on a turntable which turns the pallet and moves it to a lifting device cage by means of telescopic chain conveyor. The lifting device lifts the pallet to appropriate floor where the pallet is stored in a rack cell on either side of the lifting device by a chain conveyer.

When the pallet with car is shifted from the lifting device cage to rack cell by means of the chain conveyer, the speed of its horizontal move is controlled by a frequency controller which controls the speed of a chain conveyer drive unit. The pallet with car must be parked in the rack cell in proper position where the pallet is secured against spontaneous movement when the brake pulley is engaged in the brake haunch cut-out.

The brake pulley is swivel seated on a pin which is pushed through a pulley holder holes. The pulley holder is linked with the brake body by means of a coil compressive spring of controllable pre-stressing. It happens very frequently that software controlling the speed of the pallet and car shifting into the parking position in rack cell causes that the brake pulley fails to engage the brake haunch cut-out, i.e. that the pallet fails to reach the parking position as required, or, that the brake pulley is pushed out of the brake haunch cut-out and pallet overruns the proper position. To avoid such undesirable condition when the brake pulley is not guided accurately to the brake haunch cut-out by the chain conveyor and horizontal move of the pallet is not stopped at this position, applying a transducer is recommended.

The paper outlines the design of testing equipment for pallet arresting system the purpose of which is to verify whether the application of transducers which would transmit information on the reach of parking position to control system is suitable.

The paper describes the process of calibration of strain-gauge based transducers to be applied in the testing equipment for obtaining the information on the horizontal and vertical forces acting on the pallet brake when the brake pulley rolls on the brake haunch [13], and information on the magnitudes of forces acting when the brake pulley is pushed out of the brake haunch cut-out.

The paper also describes experimental measurements of the coil compressive spring compression in relation to the pushing force applied and evaluation using Student's $t$-distribution of the spring constant actual value applicable in the pallet brake.

Acknowledgement: This work has been supported by The Ministry of Education, Youth and Sports of the Czech Republic from the Specific Research Project SP2019/101 and a Contract for work No. S40/19-342-01.

\section{References}

[1] Westfalia Technologies Inc., Westfalia Logistics Solutions https: //www.westfaliaparking.com/parking-systems/system-types/

[2] KLAUS Multiparking GmbH https://www.multiparking.com/index. php?Products-carstacker-doubleparker-main1

[3] KOMA - Industry s.r.o., Komaparking http://www.komaparki ng.cz/koma-tower/

[4] Hrabovský L., Mlčák T., Kotajný G., Forces Generated in the Parking Brake of the Pallet Locking System, Advances in Science and Technology Research Journal, Adv. Sci. Technol. Res. J. 2019; 13(4)

[5] COMFORIA, s.r.o., Tenzometry http://tenzometry.eu/comforia /index.php?nahled_snimace $=7$ 
[6] UNIMETRA, spol. s r.o., Unimetra http://www.unimetra.cz/ soubory zbozi/84_14.pdf

[7] EICHLER COMPANY a.s., Eichlercompany https://www.eichler company.cz/pruziny/vinute-pruziny/pruzina-r-1/vinuta-pruzin a-s551371782

[8] Hrabovský L., Maslarić M., Device designed for detection and setting the required tensile force in ropes, Advances in Science and Technology Research Journal, 2018, 1, 200-206

[9] TrueTech s.r.o., Primadilna https://www.primadilna.cz/Digitalnisnimac-polohy-horizontalni300-mm-Warco-d2605.htm
[10] Mádr V., Knejzlík J., Kopečný J., Novotný l., Physics measurement, SNTL Praha 1991, 304

[11] Molnar V.; Fedorko G.; Stehlikova B., Mathematical models for indirect measurement of contact forces in hexagonal idler housing of pipe conveyor, MEASUREMENT, 2014, 7, 794-803

[12] GME 2019 https://www.gme.cz/data/attachments/dsh.631-5 18.1.pdf

[13] Hrabovský L., Mlčák T., Vertical Forces Acting on the Lock-Off Element of the Pallet Brake System, Advances in Science and Technology Research Journal, Adv. Sci. Technol. Res. J. 2019; 13(4) 